\title{
"I felt like I was really talking to you!": intimacy and trust among teen vloggers and followers in Portugal and Brazil
}

\section{Lidia Marôpo, Ana Jorge \& Renata Tomaz}

To cite this article: Lidia Marôpo, Ana Jorge \& Renata Tomaz (2020) "I felt like I was really talking to you!": intimacy and trust among teen vloggers and followers in Portugal and Brazil, Journal of Children and Media, 14:1, 22-37, DOI: 10.1080/17482798.2019.1699589

To link to this article: https://doi.org/10.1080/17482798.2019.1699589

曲 Published online: 09 Dec 2019.

Submit your article to this journal

山ll Article views: 128

Q View related articles $\sqsubset$

View Crossmark data $₫$ 


\title{
"I felt like I was really talking to you!": intimacy and trust among teen vloggers and followers in Portugal and Brazil
}

\author{
Lidia Marôpo $\mathbb{D}^{\mathrm{a}, \mathrm{b}}$, Ana Jorge $\mathbb{( D}^{\text {c,d }}$ and Renata Tomaz $\mathbb{D}^{\mathrm{e}}$
}

aHigher School of Education, Department of Communication and Language Sciences, Polytechnic Institute of Setúbal, Setubal, Portugal; ' 'Interdisciplinary Centre of Social Sciences - CICS.NOVA, Colégio Almada Negreiros, Lisbon, Portugal; 'Communication Department, Human Sciences Faculty, Catholic University of Portugal, Lisboa, Portugal; ' ${ }^{\mathrm{C} C o m m u n i c a t i o n ~ S c i e n c e s ~ D e p a r t m e n t, ~ S o c i a l ~ a n d ~ H u m a n ~ S c i e n c e s ~ F a c u l t y, ~ N e w ~}$ University of Lisbon, Lisbon, Portugal; 'Department of Cultural Studies and Media, Fluminense Federal University, Niterói, Brazil

\section{ABSTRACT}

This paper analyzes how female teen YouTubers manage intimacy and trust in the narration of their personal lives and the ways in which this is perceived by followers. The analysis of two case studies of popular teen YouTubers from Portugal and Brazil - SofiaBBeauty and Manoela Antelo, respectively - revealed that their presentation is anchored in discourses about whom they are with and where they are, what they are doing, and their personal tastes and styles. Through their comments on the videos, followers express trust connections with the vloggers, based on a sense of proximity, a desire for exclusivity in their relationship, relatability with banal aspects, and recognition as cultural intermediaries. These case studies have demonstrated strong similarities in the vloggers' practices of constructing intimacy and consequent trust with peer audiences, bearing great resemblance with older YouTubers from central cultures. Although Sofia and Manoela put forward different class performances, the trust they inspire in their followers is a fundamental form of capital for both.

\section{ARTICLE HISTORY}

Received 25 September 2018

Revised 15 November 2019

Accepted 20 November 2019

\section{KEYWORDS}

Micro-celebrity; youth; vlogger; intimacy; trust; influencer; YouTube; YouTuber; teenagers; girlhood

\section{Introduction}

Successful young YouTubers are seen as role models by their significant numbers of peer followers (Westenberg, 2016). They share their experiences, feelings, and opinions, promoting affective and trustful relations with their audiences. This explains why teenagers feel they can more easily relate with micro-celebrities they follow than with traditional celebrities from the movies or television industries (Defy Media, 2015), engaging in what Abidin (2013) calls a "perceived interconnectedness" with digital performers. Content producers articulate digital technologies of intimacy (Berryman \& Kavka, 2017) marked by an aura of authenticity, proximity, and self-disclosure to promote closer and trustful forms of sociability with their followers. These tactics are easily seen in an emblematic genre on YouTube: vlogs, video diaries made by talking to the camera or in documentary style (Bakioğlu, 2018, p. 6).

CONTACT Lidia Marôpo lidia.maropo@ese.ips.pt @ Polytechnic Institute of Setúbal, Campus do IPS - Estefanilha, Setubal 2910-761, Portugal

This article has been republished with minor changes. These changes do not impact the academic content of the article. (c) 2019 Informa UK Limited, trading as Taylor \& Francis Group 
Studies on micro-celebrities or social media influencers have been focused on young adults and on their modes of self-presentation (Abidin, 2015; Aran, Biel, \& Gatica-Perez, 2014; Berryman \& Kavka, 2017; Bruijn, 2016; García-Rapp, 2017). This article seeks to contribute to the discussion of the role of teen micro-celebrities in youth culture. We analyze the intimacy strategies used by female teen YouTubers to build trust with their audiences, and the online interactions between them. For this purpose, we consider two cases from two different and semi-peripheral cultural contexts: the very popular channels Manoela Antelo, from Brazil, and SofiaBBeauty, from Portugal. While part of a developed region of the world - Europe -, Portugal is on the periphery of that region and far from the development of Central and Northern European countries; Brazil is the biggest country in South America and an emergent economy, yet facing structural problems of development. We will unpack the role played by trust in the accumulation of capital by these young content producers, who position themselves as self-entrepreneurs in a global post-feminist digital culture.

\section{From produsage to professionalization on YouTube}

Since its advent, web 2.0 has opened up the possibility for users to become producers of content, or "produsage" (Bruns, 2006). For some, this was a cultural moment to celebrate, since it increased opportunities to contribute to a "participatory culture", in the phrase coined by Jenkins (2006), and thus promoted the democratization of content creation.

Increasingly, however, social media and notably YouTube have stopped being solely about ordinary user-generated content (UGC) in a democratic or egalitarian sense. As Van Dijck and Poell (2013) note, popularity is one of the driving elements of social media logics, bringing special produsers to the forefront. Ordinary produsers deploy micro-celebrity, the concept advanced by Senft (2013) to make sense of camgirls' modes of visual narration to seek online visibility and later expanded by Marwick and Boyd (2011) to the Twitter environment. Users emulate traditional celebrity presentation in social media as the latter facilitate proximity and immediacy (Marwick \& Boyd, 2010). They present themselves as ordinary and authentic, use "strategic intimacy to appeal to followers, and regard their audience as fans" (Marwick, 2015, p. 333). Micro-celebrity refers to the communicative practice of self-presentation but has also come to signify the status and the people using it (Jorge \& Nunes, 2019).

Crucially, this popularity "is conditioned by both algorithmic and socioeconomic components" (Van Dijck \& Poell, 2013, p. 7, original italics) and, "as platforms like Facebook and Twitter matured, their techniques for filtering out popular items and influential people became gradually more sophisticated" (p. 6). This process also extends to YouTube, where the logic of content itself in its early days as a video-sharing site gave way to the prevalence of producers/channels as it consolidated its social media logics.

The monetization of content on social media is dependent on the involvement of audiences (Arthus, Drakopoulou, \& Gandini, 2018). On YouTube, "stars matter (...): those that rise, hold, and grow large follower bases are important players in ensuring revenue generation from UGC" (Postigo, 2016, p. 345). YouTube has thus invested greatly in transforming YouTubers into "credible content creators": offering them advice, creating the Partners programme to offer a share of the revenue obtained from advertising (Cunningham \& Craig, 2017), and launching YouTube Spaces, well-equipped studios and meeting rooms available to registered content producers in several cities around the world. 
Among social media, "YouTube as a platform plays a crucial role by persistently encouraging users to compete for attention and status and rewarding them economically for promoting themselves" (Raun, 2018, p. 100). Hou notes that "more and more homegrown YouTube stars are turning into professional content creators" (2019, p. 535), with regular video releases, sophisticated production, sound/image material and editing. YouTube's ranking algorithm promotes this professionalisation, as the logics of trending videos favor those creators who are more regular (Van Dijck \& Poell, 2013).

Commonly, social media produsers seeking to maximize their visibility use a variety of social media platforms and their different affordances to promote their online personae. They engage "in content innovation and media entrepreneurship across multiple social media platforms to aggregate global fan communities and incubate their own media brands" (Cunningham \& Craig, 2017, p. 71). Thus, the term "(social media) influencer" refers to

"everyday, ordinary Internet users who accumulate a relatively large following on blogs and social media through the textual and visual narration of their personal lives and lifestyles, engage with their following in digital and physical spaces, and monetise their following by integrating "advertorials" into their blog or social media posts" (Abidin, 2015).

In popular and media discourses, influencers have come to be seen mostly as people who associate with commercial and non-commercial brands as a profession, in a heavily commercialized environment (Khamis, Ang, \& Welling, 2017). The close, intimate relationship established between popular content producers and their followers is crucial for brands, which immerse themselves in personal narratives to reach consumers (Hearn \& Schoenhoff, 2016; Hou, 2019). YouTubers are perceived as egalitarian and authentic; their intimate stories make them seem approachable and trustworthy (followers believe that their recommendations or criticisms are honest); they are close in age to their audience and so are assumed to be more easily capable of creating content that fits their current frame of reference; and they can easily interact with their followers (Andò, 2016; Westenberg, 2016). In this sense, YouTubers are an important part of children's media usage, since they are seen as a source of information and informal learning, consequently playing a role in their followers' consumption practices (Martínez \& Olsson, 2019).

In this attention economy (Senft, 2013), the attention gleaned and the intimacy and trust obtained are transformed into financial capital (Hearn \& Schoenhoff, 2016; Marwick, 2015). In what is also termed "the like economy", metrics include numbers of subscribers, views, "likes", and replies as indicators of following and engagement (Berryman \& Kavka, 2018; Hutchinson, 2017). As a result, the video-sharing platform became an ideal space to craft the self-as-brand (Bakioğlu, 2018). Self-presentation goes hand in hand with selfcommodification, borrowing from previously existing strategies and logics of commercial brand culture (Banet-Weiser, 2011). However, it is also crucial that content producers project themselves as passionate and uncalculating workers (Duffy \& Hund, 2015).

Although they play a part in the commodification of online culture, the cultural significance of these personalities is not restricted to the commercial aspects, but also extends to their role as "cultural intermediaries". Hutchinson (2017) updates the concept created by Pierre Bourdieu, describing social media influencers as "new taste agents" (p. 2), engaged in bridging the production and consumption of symbolic goods and services. They step into a process of "convergence between social media technologies, cultural knowledge and 
experiences, and users" (p. 8) and position themselves as savvy entrepreneurs, able to navigate the platforms' policies and to adapt norms, language and style (p. 7).

\section{Intimacy and girlhood on YouTube}

The gendered dimension of content production on YouTube has been the focus of attention in recent academic studies (Andò, 2016; Banet-Weiser, 2011; Berryman \& Kavka, 2017; Lange, 2014; Marôpo, Sampaio, \& Miranda, 2018; Yarosh, Bonsignore, McRoberts, \& Peyton, 2016). Potential benefits are highlighted, including creative identitymaking on the Internet, public visibility of girlhood cultures, peer recognition and opportunities to improve girls' self-presentation and technical skills. Nevertheless, these studies emphasize the complexity of girls' presentation online (Banet-Weiser, 2011) while also highlighting their growing involvement with the "proto-industry of social media entertainment" (SME) (Cunningham \& Craig, 2017). Public recognition, as measured by the numbers of subscribers, views, comments, and "thumbs up", is a clear goal for popular girl YouTubers strongly marked by the values of a widespread confessional culture (Matthews, 2007) and by a femininity in which commodification supports the construction of a mediated intimacy (Berryman \& Kavka, 2017; Duffy \& Hund, 2015).

The management of intimacy to construct a trustful emotional connection with followers is essential in this digital influencer model. A sense of intimacy is curated by emphasizing an ordinary, everyday personae, sharing personal information and making an effort to appear familiar and close to followers (Senft, 2008). Thus, influencers intentionally use digital media to craft, convey, and sustain intimacies with their followers in different ways (commercial, interactive, reciprocal, disclosive) (Abidin, 2015).

Andò (2016) found that the relevance of female Italian vloggers in the lives of adolescents, as they transition from childhood to adulthood, is attributable to several aspects of authenticity. These include the lack of any specific talent or outstanding characteristic in the videos, the domestic context represented, the conversational and interpersonal nature of the content, the amateur nature of the videos, the range of topics presented and their relevance to teenagers, the vloggers' proximity, the perception of authenticity (linked to sincerity, spontaneity and normality) and the presumption of these figures as models. The brands are imbricated in this context, providing a common language and generating social ties and elements to share and recognize (Jorge, Marôpo, \& Nunes, 2018).

Feminist scholars argue that these strategies of authenticity and intimacy are crucial elements in the construction, marketing, and consumption of feminine subjectivity (Genz, 2015). This has also been found among girl YouTubers in the transition from childhood to adolescence. Famous girl vloggers in Brazil describe their tastes, thoughts, feelings, and experiences in discourses about mundane topics such as fashion and beauty routines, choice of room decor, family relationships, school life, and their performance as YouTubers (Marôpo, Sampaio \& Miranda, 2018). In these discourses, formats around playfulness mingle with what they call an "emergent femininity".

The intimacy shown, however, is not that which arose in the eighteenth century, in which individuals needed to look inside themselves and find ways of expressing their subjectivity, so as to become a unique being (Tomaz, 2019). Intimacy lies in the distinct ways that individuals do ordinary things: drink coffee, put on make-up, play, dress up for a party, study. The unpretentious or banal helps to construct what Goldsmith (2011) calls an oblique 
autobiography: trivial information leaves clues and helps the viewer to construct a narrative about the youtuber. These banal - and relatable - aspects, however, are combined, in the self-branding of fashion bloggers, with more glamorous ones, portrayed as exclusive and thus aspirational (Duffy \& Hund, 2015).

To Abidin (2013), there is a "commercial intimacy" that is established between (lifestyle) bloggers and readers - "based on the blogger's personal life as the commodity that is being traded and vicariously consumed". This is the product of "intimacy labor" in which the followers are invited "to interact with influencers (...), to contribute to the curation of influencer content from informal polls (...), and to improve influencer content through solicited feedback". Meanwhile, influencers also set boundaries on the topics they can talk about - or not. Abidin (2013) gives the name 'perceived interconnectedness' to this model of communication in which influencers interact with followers to give the impression of intimacy and an "illusion of 'reciprocity and rapport' between a sincere persona and a loyal audience". Focusing on lifestyle influencers, she claims that "perceived interconnectedness" is grounded in four characteristics: immediacy (the need to respond quickly to readers), constancy (the expectation from readers that bloggers are always online), exclusivity (the expectation on the part of the audience that they will have their question answered personally and directly), intimacy (demands for increasing levels of disclosure about the influencer's life) and quality (the need to respond in a thoughtful way to audiences' requests for advice and information).

However, sustaining a relationship of trust with the audience while engaging with brands is also a challenge for the vloggers. Bruijn (2016) describes the strategies used by 25-year-old UK-based blogger and vlogger, Susannah Bonaldi: 1. she duplicates the gestures, conversational style, and milieu of an informal face-to-face gathering; 2 . she often faces the audience, directly addressing them and talking as if in a private personal conversation; 3. she shares information about her private life and her personal experiences with products; 4 . she reveals messy details, mistakes and her amateur status in her videos; 5. she discloses sponsored content, shares details about her engagement with brands and goods, emphasizing that her experiences are personal and not influenced by the brands and sponsorships. In response, her followers comment, show mutual selfdisclosure or give opinions and feedback when asked. Nevertheless, the YouTuber herself rarely participates in the comment section.

These studies show how intimacy and authenticity are an essential part of the apparent reliability of micro-celebrities, becoming cultural, social and economic capital. In this scenario, gender empowerment is connected with trust-building among audiences and with consumer culture in the individualistic logic of self-entrepreneurship in online spaces.

\section{Methods}

This article draws on a cross-cultural case study analysis to examine how female teen YouTubers manage intimacy and trust with their audiences. We do so through content analysis of vloggers' and followers' publicly visible interactions. Specifically, we ask: how do young YouTubers craft intimacy and how does this position them in relation to their followers? How do followers negotiate and express trust in the YouTubers? What are the cultural and age specificities of the YouTubers? 
Since most of the literature relates to English-language and central cultures, and on single cases, this article pays attention to contexts that are at the semi-periphery of global cultural production, and takes a cross-cultural stance. We thus seek to answer these questions by exploring the particularities of teen YouTubers at a stage of semiprofessionalization in Portugal and Brazil, countries in different continents but united by postcolonial ties and sharing the Portuguese language, the world's sixth most widely spoken. One case per country was chosen, with purposive criteria in mind: within different stages of adolescence, below the age of 18 , and with a consistent record on YouTube in terms of longevity and popularity in their respective countries. The Portuguese case is SofiaBBeauty, by 17-year-old (in 2017) Sofia Barbosa (https://www.youtube.com/user/ SofiaBBeauty), a beauty and fashion YouTube channel started in 2012, when she was 12 . The channel has expanded into lifestyle, including beverages, food, and cultural products. Each of her videos has an average of 50,000 views (Cardoso, 2017) and in 2017 she won the Nickelodeon Kids' Choice Awards for Portugal (Jorge et al., 2018). In April 2018 her channel had around 225,000 subscribers (in a country with 10 million inhabitants).

The Brazilian case is Manoela Antelo (https://www.youtube.com/channel/ UCL9vKk4ldu5DVDbNbbev1lg), a channel by a 12-year-old girl that has had almost 300 million views. Manoela started her channel in 2013, aged 8, with her uncle's help. She lives in the periphery of Rio de Janeiro, in a "new middle class" family of the kind generated by the economic development of Brazil over the last decade. Her videos show her daily life and often apparently spontaneous contexts of play and rides full of humor and mockery. As Manoela has gone from childhood to adolescence, the channel has gradually become more confessional and more focused on her lifestyle (Marôpo, Sampaio, \& Miranda, 2017; Tomaz, 2019). By April 2018, Manoela Antelo had amassed 1.5 million subscribers (in a country with more than 200 million inhabitants, and which ranks as the second highest in terms of YouTube usage worldwide - Statista, https://www.statista.com/statistics/280685/number-ofmonthly-unique-youtube-users/), and has guest-starred on mass-audience shows on television, a medium that is central to Brazilian culture.

Qualitative content analysis was conducted (Neuendorf \& Kumar, 2015). The corpus was composed of the most popular video blog of each month in 2017 on each of the two channels, and comments on them. Video blogs most typically include "an individual speaking to the camera in monologue style" indoors, but also evolved to "a mobile 'follow-me' style (...) to document" daily activities and hobbies outdoors (Snelson, 2015, p. 322). Thus, this format was purposively sampled as it is not only very frequent on the channels but also particularly confessional. Each video was watched and transcribed in an extensive summary with special attention to the ways in which the YouTubers negotiate intimacy and trust with their audiences. Information on the length of the video, and the numbers of views, likes, dislikes, and comments were also collected (in May 2018) ${ }^{1}$.

We performed a thematic analysis on the vlogs and comments, partly based on the literature, partly by induction (Corbin \& Strauss, 2008). The vlogs' first level of themes clustered around spaces and people depicted in the videos, personal style as represented through commodities, and cultural consumption. The typology of themes for the interaction between the YouTubers and their followers builds on Abidin (2013) and Bruijn (2016): we identified comments expressing the feeling of proximity to the vloggers; wishes for some exclusivity in their relationship; appreciation of relatability with the YouTubers; and seeking or appreciating guidance from them. We analysed the video 
contents and followers' reactions in two major themes: "where I am is close to you", and "follow me and trust my taste".

\section{Results}

SofiaBBeauty and Manoela Antelo publicly and intensively promote and disseminate their videos with a careful management of their public images: the opening intros and logos in their YouTube videos and their pictures on other social media sites (such as Facebook, Twitter, and Instagram) indicate careful production aimed at creating a strong visual identity. As teenagers, they are semi-professional content producers monetizing their stories of growing up. As they share their daily experiences and opinions, they seek to position themselves as personae close to their peer followers. At the same time, lifestyle and consumption play a prominent role in their narratives. Next, we break down the prevailing themes of their self-presentation by looking at how they project intimacy and trust and the ways in which followers express their perceptions of this.

\section{Where I am is close to you}

The intimacy crafted by Sofia and Manoela is strongly anchored in the exhibition of domestic scenarios and daily life experiences. Sofia records in different rooms of her house and it is possible for the audience to become familiar with certain objects and furniture. She frequently presents herself in everyday and intimate moments: for instance, she records upon waking up in the morning while still half-asleep and no make-up on or late at night talking softly, apparently so as not to wake up the family. The place where she is staying seems to be so important that Sofia also shows and describes in detail her hotel room when in California to receive the Nickelodeon award as Portugal's best teen YouTuber and her AirBnB apartment after traveling to Lisbon with her sister.

Manoela's most frequent scenarios include not only her house, but also those of her grandmother and her uncle and aunt Luan and Paola, whom she visits often. When she travels with her family, the place where they stay could be the main topic of her videos. In "Tour of the house/Carnival - Manoela Antelo", the YouTuber explains that her extended family has rented a house, gives their names and says she is in a bikini and still with her hair wet because she had been in the pool. She shows the property, starting at the main gate, while family members occasionally appear: the garden, the balcony and the rooms where her family are staying, emphasizing how "messy" her room and those of her peer relatives are, so as to differentiate them from adults. The mother, who is filming, says: "folks, pay no attention to the mess" and Manoela is keen to emphasize: "I did not arrange anything to film. It's super-natural".

The bedroom, in particular, is the most valued setting and sometimes a highlighted topic of conversation (about the style of decor or arrangement, for example), confirming it as "crucial to the formation and representation of (specifically) female adolescent identity" (Berryman \& Kavka, 2017, p. 6). Even in documentary vlogs (Bakioğlu, 2018; Snelson, 2015) that occur in different places, the video usually starts in the bedroom. The bedroom is also the backdrop when vloggers disclose some behind-the-scenes information and talk as if in a private conversation, for example, revealing that they are sick. Sofia announces "I just coughed a lot, so my eyes are watery and prepare yourself for my voice because it's not very good ... Today I just wanted to sit here and talk". In a similar way, in the video "Fidget 
spinners - my collection" Manoela coughs a lot and says she has a sore throat. States of health presented publicly reinforce closeness as followers become aware of subjects that used to be private.

In response, followers strongly value this apparent spontaneity and the disclosure of YouTubers' private information, showing a sense of proximity they frequently want to enhance. A fan of Sofia says she likes Q\&A very much because it is useful "to get to know her better". Another fan comments: "I'm really happy to see these videos when you just let off steam with us". And many ask for more: "I felt like I was really talking to you! please make more videos like this!". Manoela's followers frequently praise her for sharing several aspects of her life and family with them: "thank you for talking about yourself[,] you are awesome". Some of them also feel trustful enough to ask intimate and potentially embarrassing questions: "Manu, I know this is a very intimate question, and excuse me for it, but did you have your period already?", one comment reads.

This sense of closeness is fed by domestic incidents that contribute to an air of authenticity, far from staging: the phone call from the mother or the sister who passes by and drops objects, making a noise (Sofia); or the 3-year-old brother suddenly entering the room (Manoela).

In this sense, their families frequently appear in what seem to be spontaneous interactions. In all but one video in the corpus, Manoela does not appear alone. Even in those in which only she appears in the frame, there is an intervention by family members whether a brief insertion into the environment or a conversation with the YouTuber from behind the camera. In the video in which she is filming herself to show off her collection of spinners, her stepfather knocks on the bedroom door to say good night and she asks him to also greet "the folks", which he promptly does.

On Manoela's channel, her uncle Luan and his wife Paola, as well as her mother, stepfather, and younger brother are constantly present. They engage in play, comedy and vlogs, talk, make suggestions, send kisses to followers, and share messages. The presence of such figures is so commonplace that the channel is often called the Antelo Family channel by her followers:

This is the channel of the Antelo family!

Loved the video manuuu !!! love you so much. I love EVERYONE in the ANTELO family, you make my day, kss

Sofia's family also often appears in her videos, although only in passing and without major roles. She frequently mentions that she is with her mother or sister, but the public only sees brief flashes of them. Nevertheless, it is sometimes possible to see displays of close affection between her and her relatives, such as in her birthday vlog, after the dinner with her family when she talks to her brother João.

And did you like the food?

João: I really enjoyed it. 17 , is it weird?

Sofia: It's not for you, it's for me. Only one year to go to 18 .

João: It's true. But for me you'll always be my little baby.

(Sofia laughs with embarrassment.) 
Besides the most frequent home-based vlogs, video settings also include school (where we can see Manoela waiting for exam results with peers or Sofia leaving school with friends), their neighborhood (the street where they live or surrounding buildings), urban public spaces (more frequent in Sofia's videos, probably because Manoela is younger and lives in a less safe place) and travel destinations (within Brazil in the case of Manoela, and sometimes international in Sofia's videos - in both cases usually sponsored).

As witnesses of vloggers' oblique autobiography (Goldsmith, 2011), the followers express affective bonds with them and often ask for a more exclusive relationship. Some of Manoela's followers ask for special greetings and kisses: "Manoela Antelo send me a kiss in your next video please"; "Send kisses to me pleease manu \#noticeme love ya $<3$ ". Others express the ambitious desire of having Manoela as a follower of their own channels: "Manoela Antelo pls stop by my channel[,] I created it because of you[,] I love your videos".

Sofia's followers are usually more mature, not least because Sofia is around five years older than Manoela, and frequently write long comments in which they paradoxically present themselves in the position of a fan while at the same time craving the establishment of friend-like relations with the YouTuber:

Obviously I will look like a pest but I would like you maybe to be able to help me or even film with me, if by some miracle you'd be interested in watching my video (which would be really cool!) you just have to click on the link: https://www.youtube.com/ ... I really like your videos and since I've been watching you you have become a friend, and it's good to get home and watch the video of a 'friend', it always makes my day a bit better $<3$

Sometimes I find myself imagining what it would be like to be with you in real life. Just as when you think of being with an artist you admire and care about and you wonder if they would like you. I don't know the future but I do know l'd love to meet you in person. (believe me we have a lot in common:)) Kissesss

Nevertheless, the requests for a more exclusive and close relationship with Sofia and Manoela seem to have little effect, since they rarely answer the comments. Most of the time, the YouTubers are out of direct reach. This lack of reciprocity is a subject of controversy among Sofia's audience. Most of Sofia's followers seem to be very understanding of how hard it would be for her to interact individually with thousands of followers: "loved iittt! it's a pity that you did not answer my comment but that's ok, there's a lot of people commenting $\boldsymbol{\varphi}^{\prime \prime}$. Some loyal followers even feel the need to defend her from more skeptical ones on her lack of engagement with followers' comments.

- Fk, Sofia does not even bother to see a few comments. I have never seen her answer anyone

- Tomás that is not true. She answers to some comments and has been putting hearts on some comments. Just do not expect her to answer to all, poor her

- Rarely man [sic]. I think a few seconds of her time could make their day for some people but often she cannot even comment once -.

- Tomás I advise you to read the comments more carefully. You cannot be so demanding. She has a life and does not have to live for subscribers. She answers some and that is good enough! 
The boundaries on proximity and exclusivity between the YouTuber and followers have been debated a few times on Sofia's channel. Sofia herself tried to gently establish some red lines around her private life. She expressed her discomfort when followers surprised her by knocking at her door, saying that this had bothered her privacy and that of her family, and gently saying that she is always available, but in public spaces. Her home, bedroom, family life and daily experience seem to be accessible only through her performance in the videos. The comments generally express trust in and support for her:

I think it is so disrespectful when subscribers go to YouTubers' homes. What an invasion of privacy! It is not fair to you. Oh well. Some people just don't get it. When you like someone you necessarily have to respect their space!

\section{Follow me and trust my taste}

Besides watching the places where they hang out and the people they are with, the audience sees Sofia and Manoela growing up through their YouTube videos in which they share their daily experiences as well as their cultural tastes in leisure and personal feminine style. In her transition from childhood to adolescence, Manoela's cultural taste is strongly marked by local influences, in music (the "One word one funk song" video in May 2017 is just one example) as well as sports (for example, in "Get ready with me Christmas" she is wearing the strip of Flamengo, one of Rio de Janeiro's big soccer clubs). These preferences help to establish her persona and are connected with the playfulness of her content, with joy and energy in challenges, for instance in "CHALLENGE GUESS THE FUNK SONG IN 1 SECOND!". Sofia, on the other hand, is very much focused on beauty and fashion, and her cultural tastes include music, cinema, and television, with strongly international - mainly American and British - references, as well as travel and food. She uses English expressions and Internet vernacular, in the titles of the videos as well as while talking (Jorge et al., 2018).

In their vlogs, both deploy conversational and tutorial formats about fashion, make-up and beauty routines, presenting and justifying their choices for products and brands. They use tags and formats mimicking other, international YouTubers, such as "Make up and Talk" (Sofia had one on "back to school" in September 2017) or "Get ready with me" (Manoela launched the "Get ready with me Christmas" in December). These tags are usually translated into Portuguese, but SofiaBBeauty sometimes also includes them in English. The use of tags reveals how pervasive formats are passing down from older and global YouTubers to younger and local ones, while further associating femininity with consumption and intimacy, possibly with the aim of winning more followers.

Sofia rarely recommends products directly and depicts her choices in individual terms, as personal inclinations arising from her own style. Her sponsored content is poorly disguised and she tries to explain to viewers that "I would never partner with a brand that I do not think is good enough for me to buy" so as to claim that all products shown align with her style and taste, even if she is sometimes paid to show them. Young Manoela mingles playfulness and an emergent femininity, for instance with heavy make-up in "Get ready with me Christmas". She uses more direct prescriptions for her viewers, saying "This is for you to go there and buy. The products are great!" or displaying the store's telephone number in the video. 
On the one hand, followers enjoy relatability and appreciate the trivial aspects in which they identify with the vloggers. For the YouTubers, vlogs on "15 facts you don't know about me!" (Sofia) or "The last day of school" (Manoela) invite viewers to relate to ordinary things in a teenager's life. They are providing their oblique autobiography (Goldsmith, 2011), where small details of their ordinary lives are amplified to definers of their personalities, while allowing for young followers to feel connected:

I loved the video! It's always good for us to get to know you a bit more, and especially in these random [sic] things that we think we're the only ones to do or feel $\Leftrightarrow \square-2)(-)$

Sofia's followers tell her "I can understand you! I'm also going to take history test! (...)", "Sofia, that makes two of us! I get stains on my clothes all the time When travelling, going out, (...) every time I can't go home to change!", or that "I also learned how to use rollerblades instead of bike xD 今". One of Manoela's followers comments that "as hard as it is to believe my favorite color is also light green", and another: "When you spoke about your birthday I was all shaky bc I'm also 11, I was also born on october 1 st and I'm also going to 6th grade". Followers signal their appreciation at finding the little ways in which they are similar to the vloggers, including commodities: "OMG! I'm sooooo happy, you have a purse like mine from parfois", one follower comments on Sofia's video. And Manoela's followers write: "my backpack is also from kipling!! - 6)्ड", "I have a ribbon like yours" and "Miguel's trunks are just like my little brother's".

On the other hand, the audience looks up to Manoela and Sofia and asks for their advice and recommendations on cultural consumption as well as commodities. They notice what the vloggers already include in their speeches or in captions, but also ask for specific details that are not mentioned. A fan of Manoela asks: "what is the name of the background music ???", just as Sofia's followers comment: "I love your musical taste", "I love the vlog! But sofia try to write the name of the songs on the caption or something like that because the songs are really really good $\square$ kissesssssss". They also ask for details about items in the bedroom or other settings: "I loved it[,] can you please tell me where are those paintings in your setting from pls $\boldsymbol{\vartheta}^{\prime \prime}$ (Sofia), and more often on products for feminine production: "Make a video to show how to make that hairstyle pls! And the makeup!! You look beautiful! Kisses.*", one fan says to Sofia, or "Manu where did you buy the thing for your ear ??", a Brazilian follower asks Manoela. These questions are sometimes answered by other members of the community, if the YouTuber does not answer, from something she has revealed in other content or on other social media.

Manoela and Sofia hold an authority among viewers as cultural intermediaries (Hutchinson, 2017). In the case of Sofia that authority exists even in food, as a follower tells her: "(...) I just love your channel!! I always use your tips and I make those recipes!! (those cupcakes were delicious) !!". Manoela receives this comment: "Manoela I get so much inspiration from you, gorgeous"; and other saying they "created my channel because of you[,] I love your videos". Users often compliment them on their "beautiful t-shirt!!" or looks and make-up, or simply the whole channel and its videos.

Occasionally, as the teenage vloggers face new experiences, they turn this around and ask for feedback in the form of advice, which may appear a way to construct humility; when they show themselves as fragile and sick, for instance, followers offer advice from their own experiences: "Manu, when you get water in your ear put some alcohol and turn 
your head down, it's very good, the water will come out and it won't inflame (6)". This helps to further create a friend-like relationship where there is some form of reciprocity.

Followers acknowledge the position of success attained by the young vloggers with their own support, and express feelings of admiration and affection for them, stating that they follow their advice/requests or are inspired by them, while they note the young vloggers' extraordinary authenticity through the very transformations of adolescence and the growth of their online reputation. Some of Sofia followers say she "hasn't changed her essence" after her rise on YouTube or that she is "so humble, and so sweeeet!!": "even after $183 \mathrm{k}$ [followers] she can be Sofia, record a great video, just talking to us!". She is perceived to be uninterested in success: for her "it's not about money or 'fame', and that she really cares for her subscribers". The young followers establish a relationship between her genuineness with her success as a social media entrepreneur, because "all her dedication" is "so deserving", and "if she continues to be humble and nice and really genuine she will be successful on YouTube and beyond!". Sofia invites this type of association when she reflects on what she does and her plans for the future:

YouTube has brought me experiences that I value a lot, that has helped me to grow up ... It's so good I already know what I want and it's working so well! ... Your support is heartwarming!

Manoela's followers also express their affection for the vlogger, frequently complimenting her as "beautiful" and "funny", with their wishes for her success as a YouTuber. They not only congratulate Manoela on her achievements on the platform, especially as she announces new records in numbers of subscribers, but also say that she deserves "all this success" and highlight the fact that her YouTube channel continues to grow in popularity, with hashtags with goals such as "\#towards2million":

Manu I love you for being this humble person who grew up. On YouTube you deserve more than 10000.000.000 million subscribers[,] gorgeous[,] love you

Oh my Manu! everytime I come to your channel, you have a new achievement, I've been following you since the video of the day you got bia [Barbie], (...) I wish you all the luck in the world and that you get many millions of subscribers because you deserve it[.] (...) Love you loads[,] I have bought a shirt [from Manoela's online store]

\section{Discussion}

Through their popular YouTube channels, Manoela (Brazil), in early adolescence, and Sofia (Portugal), in late adolescence, curate a sense of intimacy emphasizing their ordinary, everyday character while being regularly available to share personal information. The narration of their growing up through video blogs encourages a sense of close connection in their audience and invites a friend-like relationship, since followers are updated about with whom and where the vloggers are, what they are doing and what their personal tastes and styles are.

In the digital culture of YouTube and other social networking sites, followers are not only witnesses of vloggers' oblique autobiography (Goldsmith, 2011), but also made to feel like active participants in it. Manoela and Sofia are usually seen as inspiring examples of self-entrepreneurship by their followers, who celebrate their growing recognition as credible content creators on YouTube, and this seems to heighten an interconnectedness. 
Besides watching the videos and responding to the vloggers' constant requests for interaction, followers actively engage in the comments' section, where they express trust in the vloggers. Followers show a sense of proximity to the YouTubers, and sometimes feel close enough to ask intimate and embarrassing questions. They also seek exclusivity in the relationship by aiming for individual attention. The fact that YouTubers rarely show reciprocity to their followers is only occasionally questioned and most of the time loyal followers drown out the skeptical ones, arguing that it is impossible for the YouTubers to interact with so many users. Followers also enjoy relatability, delighting in any resemblance they feel with banal aspects of the YouTubers, while also leaving testimonials of affection and admiration for them. It is this trustful connection that constitutes the backdrop for the vloggers' position as cultural intermediaries, whom the young followers can ask for (and sometimes offer) guidance in different aspects of life experience, commodities, and cultural consumption.

This trustful connection is also instrumental to the monetization in which these channels are fully immersed. Sofia and Manoela build narratives describing, explaining and justifying themselves and their experiences and choices, presenting these as free and autonomous, although brands are often displayed - covertly or clearly - in sponsored content. Moving into adulthood, Sofia invests in technical quality and professionalization, and has said in a video that she did not plan to go to university so as to work full time on her career in the digital sphere, as a way of following her passion (Duffy \& Hund, 2015).

\section{Conclusions}

The analysis of these case studies has demonstrated more similarities than differences in the practices of constructing intimacy and consequent trust with the young audiences, despite the two channels being produced by teenage girls of different ages and in different contexts. The more the vloggers narrate their own life and the less staging there is (of environments or appearances), the more authentic they are perceived to be. The sincerity and spontaneity of this performed authenticity is greatly valued by the audience and rarely seen as a strategically planned production, although the vloggers carefully manage the limits of their privacy. In this sense, these two cases originating from the semi-periphery of the centers of cultural production reveal great resemblances with precisely the older producers from those central cultures.

While Manoela Antelo and SofiaBBeauty are Portuguese-speaking members in their own right of YouTube's international community of practice (Lange, 2014), they put forward different class performances. Sofia's references are mostly American and British and she positions herself as cosmopolitan through her way of speaking and traveling and through references to international brands, as an upper-middle-class young girl. Manoela's content and identity are strongly rooted in Brazilian culture, particularly with cultural products that are linked with the lower class and even socially stigmatized, such as funk. This works to position them as cultural intermediaries among peers in their local contexts, in which intimacy and trust are fundamental forms of capital. 


\section{Note}

1. We retrieved the comments on these YouTube videos using YouTube Comment Scraper (http://ytcomments.klostermann.ca), exporting them into a spreadsheet, also including comment threads (replies to comments). We considered all the comments on the videos (at 9/2/ 2018), except for SofiaBBeauty's February video, which had over 12,000 comments because it featured a giveaway/prize; in this case we considered the first, i.e. oldest 200 comments.

\section{Disclosure statement}

No potential conflict of interest was reported by the authors.

\section{Notes on contributors}

Lidia Marôpo (PhD, University NOVA of Lisbon) is Assistant Professor at Polytechnic Institute of Setúbal and researcher at CICS.NOVA. lidia.maropo@ese.ips.pt

Ana Jorge (PhD, University NOVA of Lisbon) is a Guest Assistant Professor of Media and Communications at Catholic University of Portugal and at University NOVA of Lisbon. anajorge@fch.lisboa.ucp.pt

Renata Tomaz (PhD, Federal University of Rio de Janeiro) is a Postdoctoral researcher of the Postgraduate Program in Media and Daily Life, at Fluminense Federal University, Brazil. renatactomaz@gmail.com

\section{ORCID}

Lidia Marôpo (D) http://orcid.org/0000-0003-4687-7628

Ana Jorge (ID) http://orcid.org/0000-0002-4069-6212

Renata Tomaz (D) http://orcid.org/0000-0003-1054-7934

\section{References}

Abidin, C. (2013). Cyber-BFFs: Assessing women's 'perceived interconnectedness' in Singapore's commercial lifestyle blog industry. Global Media Journal Australian Edition, 7(1). Retrieved from https://www.hca.westernsydney.edu.au/gmjau/?p=217

Abidin, C. (2015). Communicative $<3$ intimacies: Influencers and perceived interconnectedness. Ada: A Journal of Gender, New Media, and Technology, 8. Retrieved from https://adanewmedia.org/ 2015/11/issue8-abidin/

Andò, R. (2016). The ordinary celebrity: Italian young vloggers and the definition of girlhood. Film, Fashion \& Consumption, 5(1), 123-139.

Aran, O., Biel, J. I., \& Gatica-Perez, D. (2014). Broadcasting oneself: Visual discovery of vlogging styles. IEEE Transactions on Multimedia, 16(1), 201-215.

Arthus, J., Drakopoulou, S., \& Gandini, A. (2018). Researching YouTube. Convergence, 24(1), 3-15.

Bakioğlu, B. S. (2018). Exposing convergence: YouTube, fan labour, and anxiety of cultural production in Lonelygirl15. Convergence, 24(2), 184-204.

Banet-Weiser, S. (2011). Branding the post-feminist self: Girls' video-production and YouTube. In M. C. Kearney (Ed.), Mediated girlhoods: New explorations of girls' media culture (pp. 277-294). New York, NY: Peter Lang.

Berryman, R., \& Kavka, M. (2017). "I guess a lot of people see me as a big sister or a friend": The role of intimacy in the celebrification of beauty vloggers. Journal of Gender Studies, 26(3), 307-320. 
Berryman, R., \& Kavka, M. (2018). Crying on YouTube: Vlogs, self-exposure and the productivity of negative affect. Convergence, 24(1), 85-98.

Bruijn, M. (2016). Reconciling authenticity and commerciality? A descriptive study of the relationship of trust between beauty and style vlogger Hello October and her community (Unpublished Master's thesis). Utrecht University, Netherlands.

Bruns, A. (2006, June-July). Towards produsage: Futures for user-led content production. In F. Sudweeks, H. Fay, \& C. Ess (Eds..), Proceedings of the fifth international conference on cultural attitudes towards technology and communication (pp. 1-10). Murdoch, W.A.: School of Information Technology, Murdoch University.

Cardoso, M. (2017, August 26). Youtuber: A mais recente profissão dos jovens portugueses. Público. Retrieved from https://www.publico.pt/2017/08/26/sociedade/noticia/o-youtube-mudou-o-tipode-artista-que-existe-1783445/amp

Corbin, J., \& Strauss, A. L. (2008). Basics of qualitative research (3rd ed). Newbury Park, CA: SAGE.

Cunningham, S., \& Craig, D. (2017). Being 'really real' on YouTube: Authenticity, community and brand culture in social media entertainment. Media International Australia, 164(1), 71-81.

Defy Media. (2015). Acumen report: Youth Video Diet. New York: Author. Retrieved from http://cdn. defymedia.com/wp-content/uploads/2016/03/DEFY-Media_Acumen_Youth-Video-Diet.pdf

Duffy, B. E., \& Hund, E. (2015). "Having it all" on social media: Entrepreneurial femininity and selfbranding among fashion bloggers. Social Media + Society, 1(2), 1-11.

García-Rapp, F. (2017). Popularity markers on YouTube's attention economy: The case of Bubzbeauty. Celebrity Studies, 8(2), 228-245.

Genz, S. (2015). My job is me. Feminist Media Studies, 15(4), 545-561.

Goldsmith, K. (2011). Uncreative writing: Managing language. New York, NY: Columbia University Press.

Hearn, A., \& Schoenhoff, S. (2016). From celebrity to influencer: Tracing the diffusion of celebrity value across the data stream. In P. D. Marshall \& S. Redmond (Eds.), A companion to celebrity (pp. 194-212). Malden, MA and Oxford: Wiley Blackwell.

Hou, M. (2019). Social media celebrity and the institutionalization of YouTube. Convergence, 25(3), 534-553.

Hutchinson, J. (2017). Cultural intermediaries: Audience participation in media organisations. Cham: Springer International Publishing.

Jenkins, H. (2006). Convergence culture: Where old and new media collide. New York: New York University Press.

Jorge, A., \& Nunes, T. (2019). WTF: Digital ambassadors for the young generation? In -S.-S. Duvall (Ed.), Youth and celebrity (pp. 35-56). New York: Peter Lang.

Jorge, A., Marôpo, L., \& Nunes, T. (2018). 'I am not being sponsored to say this': A teen youtuber and her audience negotiate branded content [Special issue]. OBS*, 12, 76-96.

Khamis, S., Ang, L., \& Welling, R. (2017). Self-branding, "micro-celebrity" and the rise of social media influencers. Celebrity Studies, 8(2), 191-208.

Lange, P. G. (2014). Kids on YouTube: Technical identities and digital literacies. Walnut Creek, CA: Left Coast Press.

Marôpo, L., Sampaio, I., \& Miranda, N. (2017). Top girls on YouTube: Identity, participation, and consumption. In I. Eleá \& L. Mikos (Eds.), Young \& creative: Digital technologies empowering children in everyday life (pp. 65-87). Gothenburg: NORDICOM/The International Clearinghouse on Children, Youth \& Media.

Marôpo, L., Sampaio, I., \& Miranda, N. (2018). Meninas no YouTube: Participação, celebrização e cultura do consumo? [Girlhood on YouTube: Participation, celebrification, and consumer culture]. Estudos Em Comunicação, 1(26), 175-195.

Martínez, C., \& Olsson, T. (2019). Making sense of YouTubers: How Swedish children construct and negotiate the YouTuber Misslisibell as a girl celebrity. Journal of Children and Media, 13(1), 36-52.

Marwick, A. (2015). You may know me from YouTube. In S. Redmond \& P. D. Marshall (Eds.), A companion to celebrity (pp. 333-349). Chichester: Wiley Blackwell.

Marwick, A. E, \& boyd, d. (2011). I tweet honestly, i tweet passionately: twitter users, context collapse, and the imagined audience. New Media \& Society, 13(1), 114-133. doi: 10.1177/ 1461444810365313 
Matthews, N. (2007). Confessions to a new public: Video nation shorts. Media, Culture \& Society, 29(3), 435-448.

Neuendorf, K. A., \& Kumar, A. (2015). Content analysis. In G. Mazzoleni (Ed.), The international encyclopedia of political communication (pp. 1-10). Hoboken, NJ: John Wiley \& Sons.

Postigo, H. (2016). The socio-technical architecture of digital labor: Converting play into YouTube money. New Media \& Society, 18(2), 332-349.

Raun, T. (2018). Capitalizing intimacy: New subcultural forms of micro-celebrity strategies and affective labour on YouTube. Convergence: the International Journal of Research into New Media Technologies, 24(1), 99-113.

Senft, T. (2008). Camgirls: celebrity and community in the age of social networks. New York: Peter Lang Publishing.

Senft, T. (2013). Microcelebrity and the branded self. In J. Hartley, J. Burgess, \& A. Bruns (Eds.), A companion to new media dynamics (pp. 346-354). Chichester: Wiley Blackwell.

Snelson, C. (2015). Vlogging about school on YouTube: An exploratory study. New Media \& Society, 17(3), 321-339.

Tomaz, R. (2019). O que você vai ser quando crescer? Youtubers, Infância e Celebridade [What will you be when you grow up? Youtubers, childhood and celebrity]. Salvador-BA: EdUFBA.

Van Dijck, J., \& Poell, T. (2013). Understanding social media logic. Media and Communication, 1(1), 2-14. Westenberg, W. (2016). The influence of YouTubers on teenagers: A descriptive research about the role YouTubers play in the life of their teenage viewers (Unpublished master's thesis). University of Twente, The Netherlands.

Yarosh, S., Bonsignore, E., McRoberts, S., \& Peyton, T. (2016, February-March). YouthTube: Youth video authorship on YouTube and Vine. In D. Gergle (Ed.), CSCW 2016. proceedings of the 19th ACM conference on computer-supported cooperative work and social computing (pp. 1423-1437). San Francisco, CA: Association for Computing Machinery. 